\title{
Multidrug-resistant organism carriage among residents from residential care homes for the elderly in Hong Kong: a prevalence survey with stratified cluster sampling
}

\author{
H Chen *, KM Au, KE Hsu, Christopher KC Lai, Jennifer Myint, YF Mak, SY Lee, TY Wong, NC Tsang
}

\section{A B S T R A C T}

Introduction: A point prevalence survey was conducted to study the epidemiology of and risk factors associated with multidrug-resistant organism carriage among residents in residential care homes for the elderly (RCHEs).

Methods: A total of 20 RCHEs in Hong Kong were selected by stratified single-stage cluster sampling. All consenting residents aged $\geq 65$ years from the selected RCHEs were surveyed by collection of nasal swab, axillary swab, rectal swab or stool on one single day for each home. Specimens were cultured and analysed for methicillin-resistant Staphylococcus aureus (MRSA), multidrug-resistant Acinetobacter (MDRA, defined as concomitant resistance to fluoroquinolones, carbapenems, aminoglycosides, cephalosporins and beta-lactam with or without beta-lactamase inhibitors), vancomycin-resistant Enterococcus (VRE), and carbapenemase-producing Enterobacteriaceae (CPE). One third of the MRSApositive samples were selected at random for molecular typing; all positive MDRA, VRE and CPE samples were tested for molecular typing. Demographic and health information of residents including medical history, history of hospitalisation, antimicrobial usage, and use of indwelling catheters were collected to determine any associated risk factors.

This article was published on $30 \mathrm{Jul}$ 2018 at www.hkmj.org.
Results: Samples of 1028 residents from 20 RCHEs were collected. Prevalence of MRSA was estimated as $30.1 \%$ (95\% confidence interval $[\mathrm{CI}]=25.1 \%-35.6 \%)$ and MDRA $0.6 \%$ (95\% CI=0.1\%-4.1\%). No residents carried VRE nor CPE. Residents living in privately run RCHEs were associated with MRSA carriage. Non-Chinese residents were associated with MRSA carriage with borderline significance.

Conclusions: This survey provided information about multidrug-resistant organism carriage among RCHE residents. This information will enable us to formulate targeted surveillance and control strategies for multidrug-resistant organisms.

\section{Hong Kong Med J 2018;24:350-60}

DOI: $10.12809 / \mathrm{hkmj} 176949$

${ }^{1}$ H Chen *, MB, BS, FHKAM (Community Medicine)

${ }^{1} \mathrm{KM} \mathrm{Au}, \mathrm{MB}, \mathrm{ChB}$

${ }^{1} \mathrm{KE} \mathrm{Hsu}, \mathrm{BSc}, \mathrm{MSc}$

${ }^{2}$ CKC Lai, MB, ChB, FHKAM (Pathology)

3 J Myint, MB, BS, FHKAM (Medicine)

${ }^{4}$ YF Mak, MB, BS, FHKAM (Medicine)

${ }^{5}$ SY Lee, BSc, MSc

${ }^{5}$ TY Wong, MB, BS, FHKAM (Medicine)

${ }^{2}$ NC Tsang, MB, BS, FHKAM (Pathology)

Infection Control Branch, Centre for Health Protection, Department of Health, Hong Kong

Department of Pathology, Queen Elizabeth Hospital, Jordan, Hong Kong Department of Rehabilitation, Kowloon Hospital, Homantin, Hong Kong

${ }^{4}$ Department of Medicine, Queen Elizabeth Hospital, Jordan, Hong Kong

${ }^{5}$ Infection Control Team, Queen Elizabeth Hospital, Jordan, Hong Kong

* Corresponding author: ch459@ha.org.hk

New knowledge added by this study

- Prevalence of methicillin-resistant Staphylococcus aureus among residents in residential care homes for the elderly (RCHE) was higher (30.1\%, 95\% confidence interval=25.1\%-35.6\%) than that of multidrug-resistant Acinetobacter (0.6\%, 95\% confidence interval $=0.1 \%-4.1 \%)$.

- No residents were detected to be carriers of vancomycin-resistant Enterococcus (VRE) and carbapenemaseproducing Enterobacteriaceae (CPE) in participating RCHEs, despite of the fact that these RCHEs had a history of receiving discharged VRE or CPE carriers from the hospitals.

Implications for clinical practice or policy

Such information is useful for hospitals in formulation of targeted admission surveillance and infection control strategy to prevent the spread of multidrug-resistant organisms.

\section{Introduction}

Multidrug-resistant organisms (MDROs) are microorganisms that are resistant to one or more classes of antimicrobial agent. ${ }^{1}$ Infections caused by MDROs often fail to respond to standard therapy and require treatment with "big gun" antibiotics, which may be associated with higher toxicity and cost. Infection with MDROs leads to prolonged illness 
and higher mortality than more common infections. Discharging asymptomatic colonisers from hospital to the community, especially to long-term care facilities, may increase the risk of transmission among community residents. ${ }^{2}$

In Hong Kong, residential care homes for the elderly (RCHEs) are a heterogeneous group of institutions providing different levels of care for elderly people, who, for personal, social, health or other reasons, can no longer live alone or with their families. Around 9\% of the elderly population in Hong Kong requires residential care. As of March 2015, there were approximately 750 RCHEs providing over 79000 residential places for elderly people. ${ }^{3}$

Long-term care facilities are an important reservoir for MDROs. ${ }^{4}$ Risk factors from reported cases of MDRO infection and colonisation include use of indwelling medical devices, frequent antibiotic usage and prolonged hospitalisations, all of which are common among residents of long-term care facilities. $^{5}$

Methicillin-resistant Staphylococcus aureus (MRSA) is defined as $S$ aureus being resistant to penicillinase-resistant penicillins (eg, methicillin, oxacillin or cloxacillin) and cephalosporins. As a common pathogen causing health care-associated infections, MRSA has placed a substantial burden on health care resources. ${ }^{6}$ In Hong Kong, MRSA is endemic. ${ }^{7}$ More than $40 \%$ of $S$ aureus isolated in public hospitals are MRSA. Half of the MRSA carriers among hospitalised patients aged $\geq 65$ years were admitted from RCHEs. ${ }^{8}$ Prevalence of MRSA among long-term care residents in Europe ranged from $8 \%$ to $25 \%{ }^{9}{ }^{9,10}$

Multidrug-resistant Acinetobacter (MDRA) is defined as a pathogen showing concomitant resistance to fluoroquinolones, carbapenems, aminoglycosides, cephalosporins, and beta-lactam with or without beta-lactamase inhibitors. Among hospitalised patients, ${ }^{11}$ especially in intensive care units, ${ }^{12,13}$ MDRA is an important pathogen. It can cause pneumonia, blood stream infection, skin and soft tissue infection, and urinary tract infection. ${ }^{14,15}$ Data on MDRA prevalence among RCHE residents in Hong Kong are limited.

Vancomycin-resistant Enterococcus (VRE) is defined as Enterococcus faecalis or Enterococcus faecium which is resistant to vancomycin. Carbapenemase-producing Enterobacteriaceae (CPE) is Enterobacteriaceae resistant to the carbapenem class of antibiotics. Compared with Western countries, incidence of infection with emerging MDROs such as VRE and CPE is relatively low in Hong Kong ${ }^{16}$; however, in 2013, there were outbreaks of VRE among geriatric patients in public hospitals in Kowloon. These outbreaks raised concerns about the discharge of asymptomatic

\section{多重耐藥性細菌在香港安老院舍院友的帶菌情況 調查報告：分層整群抽樣式帶菌率調查 \\ 陳虹、區嘉敏、許諾、賴貫之、邱慧慧、麥英輝、李雪怡、 黃天祐、曾艾壯 \\ 引言：透過點向現患率調查檢視香港安老院舍院友多重耐藥性細菌的} 帶菌率及其風險因素。

方法：透過分層單級整群抽樣方法從九龍區選出20間安老院舍進行點 向帶菌率調查。院舍內所有 65 歲或以上的院友均獲邀參與是次調查。 研究人員於調查當日為所有參與調查院友分別抽取鼻腔、腋下和直腸 (或糞便) 樣本。所有樣本均於該院舍進行調查當日收集, 並於即日 送往化驗所培養及進行對耐甲氧西林金黃葡萄球菌（MRSA）、耐多 藥鮑氏不動桿菌（MDRA，即同時對氟喹諾酮類、碳青霉烯類、氨基 糖苷類、頭狍菌素類和 $\beta$ - 內酰胺類〔無論有否包括 $\beta$ - 內酰胺酶抑製 劑了抗生素呈耐藥性）、耐萬古霉素腸球菌（VRE）及產碳青霉烯酶 腸道桿菌（CPE）的分析。化驗所於所有從樣本培養出的MRSA中隨 機抽樣三分一, 以及所有從樣本培養出的MDRA、VRE及CPE樣本 進行分子分型分析。研究人員同時收集參與調查院友的個人及健康資 料, 包括病史、住院紀錄、抗生素及內置導管使用情況, 以調查與帶 菌相關的風險因素。

結果：在參與調查的 20 間安老院舍中, 有 1028 名院友完成是次調 查。MRSA和MDRA的帶菌率分別為30.1\%（95\%置信區間：25.1\%$35.6 \%)$ 及 $0.6 \%(95 \%$ 置信區間 : $0.1 \%-4.1 \%$ )。所有參與調查的院友 均無驗出帶有VRE或CPE。入住私營安老院舍與被驗出MRSA帶菌相 關，而非華籍院友與被驗出MRSA帶菌則呈邊緣關聯性。

結論: 是次調查提供有關香港安老院舍院友帶有耐藥性細菌的資訊, 並有助制定關於多重耐藥性細菌的監測及控制策略。

carriers back to RCHEs that may lead to further outbreaks, particularly if there is a lapse in infection control practice in RCHEs. ${ }^{17}$

There have been few local studies on the prevalence of MDRO colonisation among $\mathrm{RCHE}$ residents. ${ }^{18,19} \mathrm{~A}$ better understanding of local MDRO epidemiology in RCHE settings is important for planning surveillance and control strategies to prevent increases in MDRO prevalence among RCHE residents.

The present survey aimed to estimate the prevalence of MDROs with public health impacts such as MRSA, MDRA, VRE and CPE among RCHE residents in Kowloon City District, Hong Kong, and to examine risk factors associated with MDRO colonisation.

\section{Methods}

\section{Population and setting}

A point prevalence survey was conducted to estimate the MDRO burden among residents in participating RCHEs and associated factors of MDRO carriage. All RCHEs with a capacity of 30 residents or more in the catchment area of Queen Elizabeth Hospital and Kowloon Hospital in Kowloon City District were 
included. All residents aged $\geq 65$ years who were in the RCHE at 9 am (the reference time) on the survey day, and consented to participate were included.

\section{Sampling strategy}

A list of all 60 RCHEs in the target area was retrieved. The RCHEs were stratified by home type: 'non-private' for government-subsidised homes and 'privately run' for profit-making homes. Stratified single-stage cluster sampling was applied to select a representative sample of residents from RCHEs at the ratio of $1: 8$, which was similar to the ratio of residential beds provided by non-private to privately run homes.

\section{Sample size planning}

Sample size estimation was based on the primary objective of the study, which was to determine the prevalence of MDROs (MRSA, MDRA, VRE and CPE) in RCHEs. Prevalence of MRSA colonisation was estimated to be $18.7 \%$ based on a local study in RCHEs in $2011 .{ }^{20}$ Since no prior information on the design effect and intraclass correlation coefficient was available, a conservative approach was taken. The intraclass correlation coefficient was set at 0.025 and the design effect was set at 2, based on estimates from a previous local study on infections in RCHEs. ${ }^{21}$ Assuming the 95\% confidence interval (CI) of MRSA prevalence estimated from current study to be $\pm 3.74 \%$ (relative precision [ie, margin of error] was $3.74 / 18.7(\%)=0.2)$, the sample size required was $836 . .^{22}$

Sample size was not estimated for the prevalence of MDRA, VRE, or CPE. For MDRA, local prevalence in RCHEs was not available. From experience in hospitals, it was expected that the prevalence of MDRA would be lower than that of MRSA and higher than that of VRE.

From experience in hospitals and from admission screening data for VRE and CPE, VRE was expected to be very uncommon and CPE was expected to be even rarer in RCHEs. Based on information from the Infection Control Branch, Centre for Health Protection, which keeps statistics on patients discharged from hospital to RCHEs, there were a total of $40 \mathrm{VRE}$ carriers discharged from hospitals to RCHEs in Kowloon City District from January to September 2013. The RCHE bed capacity in Kowloon City District was 7796 at the end of September 2013; therefore, a rough estimation was made for the prevalence of VRE in these RCHEs of $0.51 \%(40 / 7796)$. On the basis of the estimated sample size for measuring MRSA prevalence in RCHE (ie, 836) the study has the power to detect VRE prevalence with point estimate of $0.51 \%$ (95\% $\mathrm{CI}=0 \%-1.20 \%$ ), with a relative precision of 1.34 .

As the median bed capacity in RCHEs in Kowloon City District is 74, assuming 60\% of RCHE residents would agree to be surveyed, a total of 1400 residents from 19 RCHEs needed to be recruited. Assuming a response rate from RCHEs of $60 \%$, at least 32 RCHEs needed to be invited to join the study.

\section{Data and specimen collection}

Invitation letters were sent to RCHEs to introduce the survey and invite them to join. For RCHEs that agreed to participate, the survey team visited the RCHE twice. The first visit was to obtain consent from residents (consent day). The second visit was to collect information and specimen from consenting residents on a single day between September and December 2015 (survey day). The RCHEs were allowed to select the survey day freely.

Residents who consented but were absent on the survey day were excluded from the survey. Potential additional residents (including those absent on the consent day but present on the survey day) were invited to join on the survey day.

A survey form was used to collect RCHE information including home type and resident information including demographics, medical history, use of indwelling catheter, history of hospitalisation, and history of antimicrobial use over the previous year. Resident information was extracted from medical records stored in RCHEs. Nearly all residents were under the care of the Community Geriatric Team of the Hospital Authority. The Community Geriatric Team records were comprehensive, including medical history, hospitalisation to public hospitals, and medication prescribed by public hospitals. Occasionally, residents would seek help from private doctors. The RCHEs keep records of private consultations, including date of medical consultation, name of doctor consulted, and medication prescribed by private doctors. We extracted the best available data from these two sources. Functional status of residents was assessed by the survey team using the Katz index..$^{23}$ The Katz index assesses independence in activities of daily living on a 7-point Likert scale from 0 to 6 , where 6 points implies total independence. The survey team consisted of doctors and nurses who had experience working in infection control for at least 1 year. Inter-rater reliability for the Katz index among members of the team during the pilot survey was assessed using the Fleiss kappa coefficient.

For each consenting resident, the survey team took the following samples: nasal swab for MRSA, axillary swab for MRSA and MDRA, stool (or rectal swab in cases when stool could not be collected) for VRE, CPE, and MDRA. A standard survey protocol on swab taking was developed and survey team members were trained for specimen collection. For the rectal swab, faeces should be evident on the 
swab. All specimens were sent to the Microbiology Laboratory of Queen Elizabeth Hospital for culture.

One third of the MRSA-positive samples were selected at random for molecular typing. All MDRA, VRE and CPE samples were subjected to molecular typing.

For missing data identified in the survey forms, the relevant RCHE was contacted shortly after the survey for remedial work. Double data entry by two different staff members was adopted to minimise data entry error. To ensure data quality, $5 \%$ of the data were selected from the cleansed dataset to check against the hard copies.

\section{Microbiological methods}

The nasal, axillary, and rectal swab specimens collected were directly inoculated onto agar plates. Rectal swabs were visually inspected for presence of faecal materials. For faecal samples, sterile swab was used to swab a viscous portion of specimens and to inoculate onto agar plates.

Screening for MRSA was performed using chromID MRSA agar (bioMérieux, Marcy-l'Étoile, France). The chromID MRSA agars were incubated at $35 \pm 2^{\circ} \mathrm{C}$ for 24 hours. Green colonies were picked for further characterisation by Gram stain, coagulase and Staphaurex latex agglutination test (Thermo Fisher Scientific, Waltham [MA], US). Methicillin susceptibility was confirmed by cefoxitin disk diffusion test.

Typically, MDRA is characterised by Gram stain, biochemical reactions, and Vitek 2 (bioMérieux) with Gram-negative ID cards. Selective cultivation of MDRA was performed using CHROMagar Acinetobacter agars with multipledrug resistant selective supplement (CHROMagar, Paris, France) which were incubated at $35 \pm 2{ }^{\circ} \mathrm{C}$ for 48 hours. Resistance to fluoroquinolones, carbapenems, aminoglycosides, cephalosporins, and beta-lactams was confirmed by disk diffusion test.

Surveillance for VRE was performed using chromID VRE (bioMérieux) agar, which were incubated at $35 \pm 2^{\circ} \mathrm{C}$ for 48 hours. Suspected colonies were characterised by Gram stain, biochemical tests, and Vitek 2 with Gram-positive ID cards. Vancomycin susceptibility was confirmed by disk diffusion test and E-test.

chromID CARBA (bioMérieux) was used to selectively recover CPE. The chromID CARBA agars were incubated at $35 \pm 2{ }^{\circ} \mathrm{C}$ for 24 hours. Gram stain, biochemical tests, and Vitek 2 with Gram-negative ID cards were used for identification of Enterobacteriaceae. Non-susceptibility to meropenem, imipenem and ertapenem were confirmed using E-tests. Presence of carbapenemase production was screened for using a modified Hodge test with meropenem and ertapenem and a combined-disc test with boronic acid and ethylenediaminetetraacetic acid. Results were confirmed with GeneXpert (Cepheid, Sunnyvale [CA], US) Carba-R assay. All disk diffusion tests were performed according to the Clinical and Laboratory Standards Institute. ${ }^{24}$

Molecular typing was performed using DiversiLab version 3.6.1 (bioMérieux). Typing procedures were performed according to the manufacturer's instructions. The cluster analysis was performed according to the guidelines provided by the manufacturer using Pearson's correlation and the Kullback-Leibler method. Isolates were categorised as indistinguishable, similar, or different.

\section{Data analysis}

R software (ver. 3.2.0; https://www.r-project.org) was used for statistical analysis. For all analyses, statistical significance was defined as $\mathrm{P}<0.05$. Descriptive statistics were computed using all data collected. The "survey" package (version 3.30-3) in $\mathrm{R}$ was used to calculate the prevalence of MDRO carriage adjusted for cluster sampling. The prevalence of MDRO carriage among all surveyed RCHEs was calculated using the "svyciprop" function from the "survey" package, which calculates the prevalence as the sample-weighted estimator of the proportion. ${ }^{25}$ The CI was calculated by a procedure closely related to that proposed by Breeze for use in the United Kingdom General Household Survey ${ }^{26}$ which is calculated as a binomial probability using the Wilson interval method, ${ }^{27}$ followed by a logit transform. ${ }^{25}$ Prevalence of MDRO carriage among individual RCHEs was calculated by dividing the number of residents positive for MDRO culture by the total number of residents surveyed in that particular RCHE. Percentages for other study variables were calculated similarly. Logistic regression with adjustments for cluster sampling was performed using "svyglm" function from the "survey" package to identify risk factors for MRSA carriage. Variables were included for multivariate analysis if $\mathrm{P}<0.25$ in univariate analysis; or if variables had been considered as risk factors of infection in previous studies, such as mobility status, ${ }^{28}$ use of medical devices, ${ }^{29}$ presence of wound, ${ }^{29}$ home size,${ }^{29}$ sex,${ }^{30}$ and recipient of Governmental Allowance (as a surrogate measurement of socio-economic status). ${ }^{31}$ Selected variables were incorporated into the multivariate regression model in descending order of effect size estimated from the univariate regression. Variables were not included to multivariate regression model if the model with additional variable showed no statistical significance in the residual sum of squares reduction.

Grouping of quantitative variables for regression modelling was based on following criteria: (i) RCHE capacity was stratified into two groups by median RCHE capacity; (ii) resident age was grouped 
TABLE I. Recruitment of RCHEs and residents

\begin{tabular}{llll}
\hline & $\begin{array}{c}\text { Non-private } \\
\text { RCHE }\end{array}$ & $\begin{array}{c}\text { Privately run } \\
\text { RCHE }\end{array}$ & Total \\
\hline RCHE recruitment & & & \\
$\quad$ Total & 6 & 54 & 60 \\
$\quad$ Invited & 6 & 50 & 56 \\
\hline RCHE consent & & & \\
$\quad$ Yes & $1(16.7 \%)$ & $19(38.0 \%)$ & $20(35.7 \%)$ \\
$\quad$ No & 5 & 31 & 36 \\
\hline Resident recruitment & & & \\
$\quad$ Total & 75 & 1445 & 1520 \\
$\quad$ No. of residents consented & $53(70.7 \%)$ & $1039(71.9 \%)$ & $1092(71.8 \%)$ \\
\hline No. of residents surveyed & $51(68.0 \%)$ & $977(67.6 \%)$ & $1028(67.6 \%)$ \\
\hline
\end{tabular}

Abbreviation: $\mathrm{RCHE}=$ residential care home for the elderly

for every 10 years; (iii) Katz index was grouped into the reference group (6 points), low dependence (3-5 points) and high dependence (0-2 points); (iv) RCHE length of stay stratified into two groups by median RCHE length of stay among surveyed residents; and (v) hospital length of stay stratified into two groups by mean length of stay reported by the Hospital Authority for 2014-2015. ${ }^{32}$

The survey was conducted in a linked and anonymous manner to avoid unnecessary anxiety or stigmatisation due to positive MDRO carriage status. ${ }^{33}$ Measures were taken during the process of preparation, specimen collection, and data processing and storage to ensure protection of participants' anonymity.

\section{Results}

We invited 56 RCHEs (50 privately run and 6 nonprivate) among the 60 RCHEs in Kowloon City District to participate in the study. Of these, 20 RCHEs joined the study (Table 1). The number of residents of the recruited RCHEs ranged from 25 to 265.

A pilot survey was conducted in one RCHE from which 45 residents joined. The Fleiss kappa coefficient of the total Katz index was 0.977, and scores for individual items ranged from 0.972 to 1 , suggesting good inter-rater reliability among all members of the survey team.

Including those who participated in the pilot, 1520 eligible residents were invited and 1092 consented to participate in this survey (consent rate, $71.8 \%$ ). Consent could not be obtained from the remaining 428 residents, either because they refused or their relatives or guardians could not be contacted.

On the survey days for selected RCHEs, 10 residents who had previously given consent refused to participate, 27 left the RCHE for personal business, 24 were hospitalised, and three were attending medical appointments. The remaining 1028 residents completed the survey.

Swabs were taken from 1028 residents on a single day (survey day) for each RCHE during the 3-month period from mid-September to midDecember 2015 (1026 nasal swabs, 1027 axillary swabs, 373 stool and 654 rectal swabs), achieving a survey rate of $67.6 \%$.

\section{Demographics and underlying co-morbidity of residents}

Among the 1028 respondents, 411 (40.0\%) were men and $617(60.0 \%)$ were women. The median age was 85 years (range, 65-104 years) and more than half $(55.3 \%)$ were aged $\geq 85$ years. The majority were of Chinese ethnicity (98.0\%). The median length of stay in RCHE was 1.8 years (range, 1 day to 23.4 years). Table 2 shows the majority did not regularly use any medical devices $(85.9 \%)$ or have any wounds (95.4\%). Almost all respondents (99.8\%) had underlying chronic diseases. The most common disease was hypertension (72.8\%) followed by dementia (38.3\%), stroke (31.3\%), diabetes (26.8\%), and ischaemic heart disease $(22.0 \%)$. Over half of respondents (58.6\%) had a history of hospitalisation in the past 12 months with a mean of 2.9 episodes of hospital admission (range, 1-16 episodes). More than half of respondents $(60.7 \%)$ had used antibiotics in the past 12 months. The most commonly used antibiotics were amoxicillin/clavulanate $(50.4 \%)$ followed by levofloxacin (12.9\%) and piperacillin/tazobactam (7.2\%). Most respondents (90.6\%) were partially or totally dependent in activities of daily living, with a Katz index of $<6$. Of the respondents, $1.36 \%$ had a history of known MDRO in the past 12 months.

\section{Prevalence of multidrug-resistant organisms}

Out of 1028 residents, 1027 were tested for MRSA with 282 positive results (prevalence adjusted for cluster sampling: $30.1 \%$; $95 \% \mathrm{CI}=25.1 \%-35.6 \%$ ). All 1028 residents were tested for MDRA and three carried MDRA (prevalence adjusted for cluster sampling: $0.6 \%$; $95 \% \mathrm{CI}=0.1 \%-4.1 \%)$. A total of 1027 residents were tested for VRE and CPE; all tested negative. Culture positive rates of MRSA for nasal swab and axillary swab were $22.1 \%$ and $10.3 \%$, respectively. Culture positive rates for MDRA for axillary swab, rectal swab, and stool were $0.1 \%, 0.2 \%$, and $0.5 \%$, respectively.

All participating RCHEs $(n=20)$ had MRSA carriers with MRSA prevalence ranging from $13.2 \%$ to $57.1 \%$ (Table 3). There were no common MRSA sources revealed by the diversified molecular typing of 54 patterns (no band difference between strains within a pattern) and 12 groups (1 band difference between strains within group). 
TABLE 2. Characteristics of surveyed residents $(n=1028)$

\begin{tabular}{|c|c|}
\hline & Data* $^{*}$ \\
\hline \multicolumn{2}{|l|}{ Age (years) } \\
\hline $65-74$ & $130(12.6)$ \\
\hline $75-84$ & $330(32.1)$ \\
\hline$\geq 85$ & $568(55.3)$ \\
\hline \multicolumn{2}{|l|}{ Sex } \\
\hline Women & $617(60.0)$ \\
\hline Men & $411(40.0)$ \\
\hline \multicolumn{2}{|l|}{ Ethnicity } \\
\hline Chinese & $1007(98.0)$ \\
\hline Non-Chinese & $21(2.0)$ \\
\hline \multicolumn{2}{|l|}{ Financial status $\dagger$} \\
\hline Governmental allowance & $742(72.2)$ \\
\hline Self-finance/family support & $286(27.8)$ \\
\hline Others & $2(0.2)$ \\
\hline \multicolumn{2}{|l|}{ Length of stay in RCHE (years) } \\
\hline$\leq 1$ & $350(34.0)$ \\
\hline$>1$ to $\leq 2$ & $197(19.2)$ \\
\hline$>2$ to $\leq 4$ & $228(22.2)$ \\
\hline$>4$ & $253(24.6)$ \\
\hline \multicolumn{2}{|l|}{ Katz index } \\
\hline 6 (Independent) & $96(9.3)$ \\
\hline 3-5 (Low dependence) & $273(26.6)$ \\
\hline 0-2 (High dependence) & $658(64.0)$ \\
\hline Missing data & $1(0.1)$ \\
\hline \multicolumn{2}{|l|}{ Use of medical deviceł } \\
\hline Nasogastric tube & $84(8.2)$ \\
\hline Urinary catheter & $56(5.4)$ \\
\hline Peritoneal dialysis & $11(1.1)$ \\
\hline PEG tube & $1(0.1)$ \\
\hline Suprapubic catheter & $1(0.1)$ \\
\hline No device & $883(85.9)$ \\
\hline \multicolumn{2}{|l|}{ Use of antimicrobial } \\
\hline Aminoglycosides & $1(0.1)$ \\
\hline Cephalosporins & $4(0.4)$ \\
\hline Penicillins & $9(0.9)$ \\
\hline Quinolones & $4(0.4)$ \\
\hline Other antibiotics & $3(0.3)$ \\
\hline Antivirals & $5(0.5)$ \\
\hline Anti-tuberculosis agents & $7(0.7)$ \\
\hline
\end{tabular}

Abbreviations: $\mathrm{PEG}=$ percutaneous endoscopic gastrostomy;

$\mathrm{RCHE}=$ residential care home for the elderly

* Data are shown as No. (\%)

† Some residents received more than I type of financial support

‡ Some residents used multiple medical devices

$\S$ Some residents had multiple wounds/stomas
TABLE 2. (cont'd)

\begin{tabular}{|lc|}
\hline & Data $^{*}$ \\
\hline Presence of wound and stoma§ & \\
\hline Bedsore & $25(2.4)$ \\
\hline Others & $16(1.6)$ \\
\hline Colostomy & $6(0.6)$ \\
\hline Ileal conduit & $1(0.1)$ \\
\hline Tracheostomy & $1(0.1)$ \\
\hline No wound & $981(95.4)$ \\
\hline Co-morbidities & \\
\hline Cardiovascular disease & $807(78.5)$ \\
\hline Neurological disease & $636(61.9)$ \\
\hline Endocrine disease & $428(41.6)$ \\
\hline Musculoskeletal disease & $318(30.9)$ \\
\hline Urological disease & $119(11.6)$ \\
\hline Respiratory disease & $86(8.4)$ \\
\hline Gastrointestinal disease & $81(7.9)$ \\
\hline Depression & $55(5.4)$ \\
\hline Haematological disease & $53(5.2)$ \\
\hline Neoplasm & $40(3.9)$ \\
\hline Miscellaneous illnesses & $246(23.9)$ \\
\hline No co-morbidity & $6(0.6)$ \\
\hline
\end{tabular}

TABLE 3. MRSA prevalence of participating 20 RCHEs

\begin{tabular}{lcc}
\hline & Type of RCHE & $\begin{array}{c}\text { Prevalence }(\%) \text { of MRSA } \\
(\mathbf{9 5} \% \mathbf{C l})\end{array}$ \\
\hline 1 & Private & $13.2(5.8-27.3)$ \\
\hline 2 & Private & $13.6(4.7-33.3)$ \\
\hline 3 & Private & $17.4(9.1-30.7)$ \\
\hline 4 & Non-private & $19.6(11.0-32.5)$ \\
\hline 5 & Private & $19.6(14.6-25.7)$ \\
\hline 6 & Private & $23.1(13.7-36.1)$ \\
\hline 7 & Private & $23.5(9.6-47.3)$ \\
\hline 8 & Private & $25.3(17.0-35.9)$ \\
\hline 10 & Private & $25.6(14.9-40.2)$ \\
\hline 12 & Private & $26.9(13.7-46.1)$ \\
\hline 13 & Private & $27.7(18.3-39.6)$ \\
\hline 14 & Private & $28.7(21.4-37.3)$ \\
\hline 15 & Private & $33.3(18.6-52.2)$ \\
\hline 16 & Private & $33.3(19.8-50.4)$ \\
\hline 17 & Private & $34.8(18.8-55.1)$ \\
\hline 18 & Private & $37.5(25.2-51.6)$ \\
\hline 19 & Private & $37.9(26.6-50.8)$ \\
\hline 10 & Private & $45.5(26.9-65.3)$ \\
\hline
\end{tabular}

Abbreviations: $\mathrm{Cl}=$ confidence interval; $\mathrm{MRSA}=$ methicillinresistant Staphylococcus aureus; $\mathrm{RCHE}=$ residential care home for the elderly 
Three residents living in the same RCHE carried MDRA. The prevalence of MDRA at this RCHE was $11.5 \%$ (95\% CI=4.00\%-28.98\%). Strain typing revealed that all three likely belonged to the same MDRA strain, as the band patterns were identical.

\section{Risk factors of multidrug-resistant organism colonisation}

Compared with the 742 MDRO non-carriers, univariate analysis revealed several factors associated with MDRO positivity (Table 4). Inclusion of RCHE capacity, governmental allowance, and indwelling urinary catheter in the multivariate logistic regression model did not provide statistically significant decrease in residual sum of squares when compared with the simpler model; therefore, the simpler model was used. This model revealed that residents from privately run RCHEs were associated with MRSA colonisation and non-Chinese residents were associated with MRSA carriage with borderline significance.

Owing to the low participation rate of nonprivate RCHEs, an additional regression model was developed with residents from only privately run RCHEs, to explore the association of different risk factors with MRSA colonisation. After comparison, no differences in terms of direction, effect size, or statistical significance were observed between the two models.

\section{Discussion}

In the present study, the survey revealed a high prevalence of MRSA among RCHE residents in Hong Kong. The prevalence of MDRA, however, remained low in the same population, and VRE or CPE was not found among surveyed residents.

All RCHEs surveyed had MRSA carriers. The adjusted prevalence of MRSA colonisation was $30.1 \%$, which is similar to that of another survey conducted in RCHEs in Hong Kong Island during the same period of time (32.2\%). ${ }^{34}$ Prevalence of MRSA was much higher than that found in previous studies in $2005(2.8 \%)^{19}$ and in $2011(21.6 \%)^{35}$ Internationally, MRSA prevalence in Hong Kong is similar to that in the US (31\%), ${ }^{36}$ but higher than that in nursing home studies in the United Kingdom $(4.7 \%)^{37}$ and in Shanghai, China (10.6\%). ${ }^{38}$

The adjusted prevalence of MDRA was $0.6 \%$. This is similar to a local hospital study conducted in 2014, which recorded a prevalence of multidrugresistant Acinetobacter baumannii of $0.57 \% .^{39}$ As all three cases of MDRA were found in the same RCHE with identical molecular typing, we suspected a common source for the three carriers. We visited the RCHE and encouraged staff to implement better infection control practices. There were no subsequent outbreaks reported. Internationally, the prevalence of MDRA is much lower than that reported in studies from the US (prevalence of multidrug-resistant $A$ baumannii was $15.0 \%)^{40}$ and Australia (prevalence of multidrug-resistant $A$ baumannii was 5.2\%). ${ }^{41}$

In RCHEs, the prevalence of MRSA is rising rapidly, and that of MDRA has the potential to rise. Thus, infection control practice in RCHEs should be enhanced. Early identification of residents carrying MDRO enables RCHE staff to implement enhanced infection control practices such as early isolation or cohorting. Hand hygiene protocols should be followed carefully by health care workers in RCHEs, especially when handling patients' food or medication; after napkin rounds; and before and after nursing care processes. ${ }^{42}$ Environmental hygiene measures, such as regular cleansing and disinfection of residents' immediate environment and frequently touched areas, are of similar importance. ${ }^{43}$

The present study identified no VRE or CPE carriers from 373 stool and 654 rectal swabs of the residents screened. This echoes an earlier study of 28 RCHEs in Hong Kong Island from July to August $2015{ }^{34}$ Among 1408 subjects screened in that study, a single resident had CPE and VRE was not detected in any screened specimens.

To contain the spread of VRE and CPE among residents in RCHEs, current practice is to inform the RCHE before a VRE or CPE carrier is planned to be discharged from hospital. The RCHE staff members are recommended to enhance infection control practices, to use designated equipment with the carrier, and to adopt modified contact precaution when providing care to the carrier. This strategy has been successful; no outbreaks have been detected among RCHEs receiving VRE or CPE carriers, and the prevalence of VRE and CPE remains low in these RCHEs. Extra resources are needed if a similar strategy is adopted to control further increases in the prevalence of MRSA and MDRA.

In the present study, residents of privately run RCHEs were more likely than residents of nonprivate RCHEs to be carriers of MRSA. This could be due to privately run RCHEs being more resourcelimited, as reflected by the typically lower staff-toresidents ratio. ${ }^{44}$

The present study also found that MRSA colonisation was more common in non-Chinese residents than in Chinese residents. This is consistent with previously published research. ${ }^{45}$ To mitigate this, future infection control training should raise awareness among RCHE staff of this issue and to adopt adequate infection control measures for Chinese and non-Chinese residents alike. 
TABLE 4. Association between MDRO carriage and characteristics of RCHE and residents

\begin{tabular}{|c|c|c|c|c|c|c|}
\hline & \multicolumn{2}{|c|}{ MDRO carriage } & \multicolumn{2}{|c|}{ Univariate analysis } & \multicolumn{2}{|c|}{ Multivariate analysis } \\
\hline & Yes & No & OR (95\% Cl) & $P$ value & OR (95\% Cl) & $P$ value \\
\hline \multicolumn{7}{|l|}{ RCHE type } \\
\hline Non-private & 10 & 41 & Reference & & Reference & \\
\hline Private & 272 & 705 & $1.77(1.34-2.34)$ & $<0.005$ & $2.22(1.12-4.41)$ & 0.038 \\
\hline \multicolumn{7}{|l|}{ RCHE capacity } \\
\hline$\leq 80$ & 84 & 196 & Reference & & & \\
\hline$>80$ & 198 & 550 & $0.95(0.56-1.62)$ & 0.840 & & \\
\hline \multicolumn{7}{|l|}{ Sex } \\
\hline Women & 169 & 448 & Reference & & Reference & \\
\hline Men & 113 & 298 & $0.92(0.60-1.42)$ & 0.693 & $0.90(0.33-2.47)$ & 0.705 \\
\hline \multicolumn{7}{|l|}{ Age-group (years) } \\
\hline $65-74$ & 34 & 96 & Reference & & Reference & \\
\hline $75-84$ & 89 & 241 & $0.84(0.34-2.07)$ & 0.693 & $0.87(0.18-4.11)$ & 0.738 \\
\hline$\geq 85$ & 159 & 409 & $1.04(0.43-2.53)$ & 0.929 & $1.14(0.27-4.77)$ & 0.723 \\
\hline \multicolumn{7}{|l|}{ Ethnicity } \\
\hline Chinese & 272 & 735 & Reference & & Reference & \\
\hline Non-Chinese & 10 & 11 & $3.96(1.84-8.56)$ & $<0.005$ & $4.58(0.98-21.35)$ & 0.051 \\
\hline \multicolumn{7}{|c|}{ Any governmental allowance } \\
\hline No & 71 & 215 & Reference & & & \\
\hline Yes & 211 & 531 & $1.18(0.61-2.28)$ & 0.598 & & \\
\hline \multicolumn{7}{|l|}{ Katz index ${ }^{*}$} \\
\hline 6 (Independent) & 18 & 78 & Reference & & Reference & \\
\hline 3-5 (Low dependence) & 61 & 212 & $1.70(0.75-3.86)$ & 0.186 & $1.73(0.30-10.09)$ & 0.312 \\
\hline 0-2 (High dependence) & 203 & 455 & $2.05(0.97-4.30)$ & 0.057 & $1.74(0.41-7.34)$ & 0.239 \\
\hline \multicolumn{7}{|c|}{ Length of stay in RCHE (years) } \\
\hline$\leq 2$ & 152 & 395 & Reference & & & \\
\hline$>2$ & 130 & 351 & $1.19(0.82-1.72)$ & 0.338 & & \\
\hline \multicolumn{7}{|c|}{ Use of antibiotics in the past year } \\
\hline No & 75 & 329 & Reference & & Reference & \\
\hline Yes & 207 & 417 & $2.27(1.54-3.35)$ & $<0.005$ & $1.62(0.64-4.09)$ & 0.154 \\
\hline \multicolumn{7}{|l|}{ Any wound/stoma site } \\
\hline No & 265 & 716 & Reference & & Reference & \\
\hline Yes & 17 & 30 & $1.75(0.84-3.65)$ & 0.125 & $1.12(0.19-6.78)$ & 0.808 \\
\hline \multicolumn{7}{|l|}{ Device use } \\
\hline \multicolumn{7}{|c|}{ Indwelling urinary catheter } \\
\hline No & 266 & 706 & Reference & & & \\
\hline Yes & 16 & 40 & $0.71(0.32-1.57)$ & 0.377 & & \\
\hline \multicolumn{7}{|l|}{ Nasogastric tube } \\
\hline No & 243 & 701 & Reference & & Reference & \\
\hline Yes & 39 & 45 & $2.00(0.97-4.14)$ & 0.059 & $1.54(0.26-9.10)$ & 0.409 \\
\hline \multicolumn{7}{|l|}{ Peritoneal dialysis } \\
\hline No & 276 & 741 & Reference & & Reference & \\
\hline Yes & 6 & 5 & $5.64(0.76-41.75)$ & 0.086 & $2.90(0.05-156.25)$ & 0.369 \\
\hline
\end{tabular}

Abbreviations: $\mathrm{Cl}$ = confidence interval; $\mathrm{MDRO}=$ multidrug-resistant organism; $\mathrm{OR}=$ odds ratio; $\mathrm{RCHE}=$ residential care home for the elderly

* Missing data in I subject 
TABLE 4. (cont'd)

\begin{tabular}{|c|c|c|c|c|c|c|}
\hline & \multicolumn{2}{|c|}{ MDRO carriage } & \multicolumn{2}{|c|}{ Univariate analysis } & \multicolumn{2}{|c|}{ Multivariate analysis } \\
\hline & Yes & No & OR (95\% Cl) & $P$ value & OR (95\% Cl) & $P$ value \\
\hline \multicolumn{7}{|c|}{ Co-morbidities } \\
\hline \multicolumn{7}{|c|}{ Cardiovascular disease } \\
\hline No & 60 & 161 & Reference & & & \\
\hline Yes & 222 & 585 & $1.23(0.84-1.81)$ & 0.261 & & \\
\hline \multicolumn{7}{|c|}{ Dementia } \\
\hline No & 170 & 464 & Reference & & & \\
\hline Yes & 112 & 282 & $1.05(0.65-1.68)$ & 0.843 & & \\
\hline \multicolumn{7}{|c|}{ Diabetes } \\
\hline No & 191 & 561 & Reference & & Reference & \\
\hline Yes & 91 & 185 & $1.56(1.04-2.34)$ & 0.032 & $1.55(0.61-3.92)$ & 0.178 \\
\hline \multicolumn{7}{|c|}{ Depression } \\
\hline No & 272 & 701 & Reference & & Reference & \\
\hline Yes & 10 & 45 & $0.44(0.20-0.94)$ & 0.036 & $0.48(0.09-2.50)$ & 0.195 \\
\hline \multicolumn{7}{|l|}{ Stroke } \\
\hline No & 195 & 511 & Reference & & & \\
\hline Yes & 87 & 235 & $1.12(0.85-1.48)$ & 0.405 & & \\
\hline \multicolumn{7}{|c|}{ Prior hospitalisation (days) } \\
\hline$\leq 7$ & 127 & 473 & Reference & & Reference & \\
\hline$>7$ & 155 & 273 & $2.35(1.30-4.24)$ & 0.007 & $1.84(0.42-8.10)$ & 0.220 \\
\hline \multicolumn{7}{|c|}{ History of MDRO carriage } \\
\hline No & 275 & 739 & Reference & & Reference & \\
\hline Yes & 7 & 7 & $2.22(0.56-8.90)$ & 0.240 & $1.61(0.10-26.08)$ & 0.539 \\
\hline \multicolumn{7}{|c|}{ History of surgical procedure } \\
\hline No & 273 & 706 & Reference & & Reference & \\
\hline Yes & 9 & 40 & $0.57(0.24-1.35)$ & 0.185 & $0.42(0.07-2.48)$ & 0.170 \\
\hline
\end{tabular}

Increased age, use of medical device, and previous MRSA colonisation or infection are risk factors that have been previously reported to be associated with MRSA colonisation. ${ }^{46}$ However, the present study did not show any statistically significance differences between MRSA carriers and non-carriers by multivariate analysis. This could be due to the small sample size or selection bias in this study. A larger study is required to identify other risk factors.

There are some potential limitations to the present study. We conducted the survey in RCHEs in Kowloon City District. This may affect the generalisation of the results to RCHEs in the rest of Hong Kong. Among 56 RCHEs invited, 19 out of 50 privately run RCHEs and 1 out of 6 non-private RCHEs agreed to join the survey; $67.6 \%$ of residents from these RCHEs participated. The low participation rate of RCHEs may reduce the representativeness of study sample to the Hong Kong population of RCHE residents. We had no information on non- participating residents for baseline characteristics comparison. Self-selection bias cannot be excluded. The sample size required to accurately assess MRSA prevalence was estimated. The actual sample size may be insufficient for risk factor identification and effect size estimation. We extracted residents' information from medical records kept by participating RCHEs; therefore, information bias due to measurement error cannot be eliminated, and missing data in the medical records may lead to bias. Prevalence of MRSA or MDRA may be underestimated as only nasal and axillary swabs were taken. Other sites such as wounds, catheter sites, groins or perianal region were not sampled. The MDRA detection sensitivity would be improved by using sterile sponges to sample multiple body sites. ${ }^{47}$

\section{Conclusions}

Emergence of MDROs is a global health threat and Hong Kong is not exempt. Residents of RCHEs are 
particularly vulnerable to MDRO colonisation or infection. Enhanced infection control is important to mitigate further increases in MDRO prevalence in RCHEs. The present study provides an understanding of the situation of MDROs in RCHEs. Further larger-scale studies on MDROs in Hong Kong are required to formulate a targeted infection control programme to prevent further spread of MDROs in the community.

\section{Author contributions}

Concept and design of study: All authors.

Acquisition of data: $\mathrm{H}$ Chen, KM Au, KE Hsu, CKC Lai, J Myint, YF Mak.

Analysis and interpretation of data: $\mathrm{H}$ Chen, KE Hsu.

Drafting of the article: $\mathrm{H}$ Chen, KE Hsu.

Critical revision of important intellectual content: $\mathrm{H}$ Chen, CKC Lai, J Myint, YF Mak, SY Lee, TY Wong, NC Tsang.

\section{Acknowledgement}

The authors thank colleagues of the Community Geriatric Assessment Team of Queen Elizabeth Hospital and Kowloon Hospital for their dedication and support. The authors also thank the health care workers of all participating RCHEs.

\section{Funding/support}

This research received no specific grant from any funding agency in the public, commercial, or not-for-profit sectors.

\section{Declaration}

All authors have disclosed no conflicts of interest. All authors had full access to the data, contributed to the study, approved the final version for publication, and take responsibility for its accuracy and integrity.

\section{Ethical approval}

The survey was approved by the Ethics Committee of Kowloon Central Cluster, the Hospital Authority, and the Department of Health. Written informed consent was obtained from all residents or from their relatives or guardians.

\section{References}

1. Institute of Medicine (US) Forum on Emerging Infections. Antimicrobial resistance: issues and options-workshop report. Washington: National Academies Press (US); 1998. Available from: http://www.ncbi.nlm.nih.gov/books/ NBK100885/. Accessed 13 May 2015.

2. Institute of Medicine (US) Forum on Emerging Infections. The resistance phenomenon in microbes and infectious disease vectors: implications for human health and strategies for containment: workshop summary. Washington: National Academies Press (US); 2003. Available from: http://www.ncbi.nlm.nih.gov/books/ NBK97138/. Accessed 13 May 2015.

3. Social Welfare Department, Hong Kong SAR Government. List of residential care homes. Available from: http://www. swd.gov.hk/en/index/site_pubsvc/page_elderly/sub_ residentia/id_listofresi/. Accessed 31 Mar 2015.

4. Strausbaugh LJ, Crossley KB, Nurse BA, Thrupp LD. Antimicrobial resistance in long-term-care facilities. Infect
Control Hosp Epidemiol 1996;17:129-40.

5. Safdar N, Maki DG. The commonality of risk factors for nosocomial colonization and infection with antimicrobialresistant Staphylococcus aureus, enterococcus, Gramnegative bacilli, Clostridium difficile, and Candida. Ann Intern Med 2002;136:834-44.

6. Boyce JM, Cookson B, Christiansen K, et al. Meticillinresistant Staphylococcus aureus. Lancet Infect Dis 2005;5:653-63.

7. Ho P, Yuen K, Yam W, Wong S, Luk W. Changing patterns of susceptibilities of blood, urinary and respiratory pathogens in Hong Kong. J Hosp Infect 1995;31:305-17.

8. Chuang V, Tsang I, Wong T. Methicillin-resistant Staphylococcus aureus (MRSA) in public hospitals in Hong Kong. Commun Dis Watch 2010;7:49-50.

9. Brugnaro P, Fedeli U, Pellizzer G, et al. Clustering and risk factors of methicillin-resistant Staphylococcus aureus carriage in two Italian long-term care facilities. Infection 2009;37:216-21.

10. Talon DR, Bertrand X. Methicillin-resistant Staphylococcus aureus in geriatric patients: usefulness of screening in a chronic-care setting. Infect Control Hosp Epidemiol 2001;22:505-9.

11. Abbo A, Navon-Venezia S, Hammer-Muntz O, Krichali T, Siegman-Igra Y, Carmeli Y. Multidrug-resistant Acinetobacter baumannii. Emerg Infect Dis 2005;11:22-9.

12. Bergogne-Bérézin E, Towner KJ. Acinetobacter spp. as nosocomial pathogens: microbiological, clinical, and epidemiological features. Clin Microbiol Rev 1996;9:14865.

13. Dijkshoorn L, Nemec A, Seifert H. An increasing threat in hospitals: multidrug-resistant Acinetobacter baumannii. Nat Rev Microbiol 2007;5:939-51.

14. Gales AC, Jones RN, Forward KR, Liñares J, Sader HS, Verhoef J. Emerging importance of multidrug-resistant Acinetobacter species and Stenotrophomonas maltophilia as pathogens in seriously ill patients: geographic patterns, epidemiological features, and trends in the SENTRY Antimicrobial Surveillance Program (1997-1999). Clin Infect Dis 2001;32 Suppl 2:S104-13.

15. Gaynes R, Edwards JR, National Nosocomial Infections Surveillance System. Overview of nosocomial infections caused by Gram-negative bacilli. Clin Infect Dis 2005;41:848-54.

16. Lo J, Wong T. Update on surveillance of multi-antimicrobial resistance. Commun Dis Watch 2011;8:98-9.

17. Choi $\mathrm{K}$, Chen $\mathrm{H}$, Wong $\mathrm{T}$. Vancomycin resistant enterococcus (VRE) in Hong Kong. Commun Dis Watch 2011;8:102-3.

18. Ho PL, Lai EL, Chow KH, Chow LS, Yuen KY, Yung RW. Molecular epidemiology of methicillin-resistant Staphylococcus aureus in residential care homes for the elderly in Hong Kong. Diagn Microbiol Infect Dis 2008;61:135-42.

19. Ho PL, Wang TK, Ching P, et al. Epidemiology and genetic diversity of methicillin-resistant Staphylococcus aureus strains in residential care homes for elderly persons in Hong Kong. Infect Control Hosp Epidemiol 2007;28:671-8.

20. Chen H, Yau C, Leung L, Hsu E, Ng H, Wong TY. Prevalence of methicillin resistant Staphylococcus aureus (MRSA) carriage among residents of Residential Care Homes for Elderly in Hong Kong. Proceedings of the Hong Kong Society for Infectious Diseases 16th Annual Scientific 
Meeting; 2012 Mar 10; Hong Kong. Hong Kong: HKSID; 2012: 11 .

21. Chen H, Chiu AP, Lam PS, et al. Prevalence of infections in residential care homes for the elderly in Hong Kong. Hong Kong Med J 2008;14:444-50.

22. World Health Organization. Tuberculosis prevalence surveys: a handbook. Available from: http://www.who.

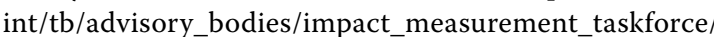
resources_documents/thelimebook/en/. Accessed 20 Jan 2015.

23. Katz S, Downs TD, Cash HR, Grotz RC. Progress in development of the index of ADL. Gerontologist 1970;10:20-30.

24. Clinical and Laboratory Standards Institute. Performance Standards for Antimicrobial Susceptibility Testing, Twenty-fifth Informational Supplement. CLSI document M100-S25. Wayne, PA: Clinical and Laboratory Standards Institute; 2015

25. Graubard BI, Korn EL. Confidence intervals for proportions with small expected number of positive counts estimated from survey data. Surv Methodol 1998;24:193-201.

26. Breeze E. General household survey, report on sampling error (based on 1985 and 1986 data). London: HMSO 1990. Available from: https://library.herts.ac.uk/cgi-bin/ koha/opac-detail.pl?biblionumber $=9939$. Accessed 3 Jan 2018.

27. Brown LD, Cai TT, DasGupta A. Interval estimation for a binomial proportion. Stat Sci 2001;16:101-17.

28. Bradley SF, Terpenning MS, Ramsey MA, et al. Methicillinresistant Staphylococcus aureus: colonization and infection in a long-term care facility. Ann Intern Med 1991;115:41722.

29. Manzur A, Gavalda L, Ruiz de Gopegui E, et al. Prevalence of methicillin-resistant Staphylococcus aureus and factors associated with colonization among residents in community long-term-care facilities in Spain. Clin Microbiol Infect 2008;14:867-72.

30. O'Sullivan NP, Keane CT. Risk factors for colonization with methicillin-resistant Staphylococcus aureus among nursing home residents. J Hosp Infect 2000;45:206-10.

31. Grundmann H, Tami A, Hori S, Halwani M, Slack R. Nottingham Staphylococcus aureus population study: prevalence of MRSA among elderly people in the community. BMJ 2002;324:1365-6.

32. Hospital Authority, Hong Kong SAR Government. 20142015 Hospital Authority Statistical Report. May 2016 Available from: http://www.ha.org.hk/haho/ho/stat/ HASR1415_1.pdf. Accessed 9 Sep 2016.

33. World Health Organization. Guidelines for measuring national HIV prevalence in population-based surveys. 2005. Available from: http://www.who.int/hiv/pub/ surveillance/measuring/en/. Accessed 21 May 2015.

34. Cheng VC, Chen JH, Ng WC, et al. Emergence of carbapenem-resistant Acinetobacter baumannii in nursing homes with high background rates of MRSA colonization. Infect Control Amp Hosp Epidemiol 2016;37:983-6.

35. Cheng VC, Tai JW, Wong ZS, et al. Transmission of methicillin-resistant Staphylococcus aureus in the long term care facilities in Hong Kong. BMC Infect Dis 2013;13:205

36. Reynolds C, Quan V, Kim D, et al. Methicillin-resistant Staphylococcus aureus (MRSA) carriage in 10 nursing homes in Orange County, California. Infect Control Hosp Epidemiol 2011;32:91-3.

37. Cox RA, Bowie PE. Methicillin-resistant Staphylococcus aureus colonization in nursing home residents: a prevalence study in Northamptonshire. J Hosp Infect 1999;43:115-22.

38. Gu FF, Zhang J, Zhao SY, et al. Risk factors for methicillinresistant Staphylococcus aureus carriage among residents in 7 nursing homes in Shanghai, China. Am J Infect Control 2016;44:805-8.

39. Cheng VC, Chen JH, So SY, et al. Use of fluoroquinolones is the single most important risk factor for the high bacterial load in patients with nasal and gastrointestinal colonization by multidrug-resistant Acinetobacter baumannii. Eur J Clin Microbiol Infect Dis 2015;34:2359-66.

40. Mody L, Gibson KE, Horcher A, et al. Prevalence of and risk factors for multidrug-resistant Acinetobacter baumannii colonization among high-risk nursing home residents. Infect Control Hosp Epidemiol 2015;36:1155-62.

41. Lim CJ, Cheng AC, Kennon J, et al. Prevalence of multidrug-resistant organisms and risk factors for carriage in long-term care facilities: a nested case-control study. J Antimicrob Chemother 2014;69:1972-80.

42. Cheng VC, Chen JH, Poon RW, et al. Control of hospital endemicity of multiple-drug-resistant Acinetobacter baumannii ST457 with directly observed hand hygiene. Eur J Clin Microbiol Infect Dis 2015;34:713-8.

43. Barnes SL, Morgan DJ, Harris AD, Carling PC, Thom KA. Preventing the transmission of multidrug-resistant organisms: modeling the relative importance of hand hygiene and environmental cleaning interventions. Infect Control Hosp Epidemiol 2014;35:1156-62.

44. Ngai YH. Institutional risk factors for influenza outbreaks in Hong Kong elderly homes: a retrospective cohort study. 2016. Available from: http://hub.hku.hk/ handle/10722/237233. Accessed 5 Dec 2017.

45. Leung YH, Lai RW, Chan AC, et al. Risk factors for community-associated methicillin-resistant Staphylococcus aureus infection in Hong Kong. J Infect 2012;64:494-9.

46. Forster AJ, Oake N, Roth V, et al. Patient-level factors associated with methicillin-resistant Staphylococcus aureus carriage at hospital admission: a systematic review. Am J Infect Control 2013;41:214-20.

47. Doi Y, Onuoha EO, Adams-Haduch JM, et al. Screening for Acinetobacter baumannii colonization by use of sponges. J Clin Microbiol 2011;49:154-8. 